\title{
To Evaluate the Effects of Tamsulosin, Solifenacin and Combination Therapy for the Treatment of Ureteral Stent Associated Symptoms
}

\author{
Dr Prakash H S $\mathbf{S}^{\mathbf{1}}$, Dr Sunil Kumar $\mathbf{V}^{2^{*}}$ \\ ${ }^{I}$ Associate Professor \& HOD of Urology, K.R. Hospital, Mysore Medical College \& Research \\ Institute, Irwin Road, Mysore. Karnataka \\ ${ }^{2}$ Department of General Surgery, K.R. Hospital, Mysore Medical College \& Reseach Institute, Mysore \\ *Corresponding Author: Dr Sunil Kumar V, Department of General Surgery, K.R. Hospital, Mysore \\ Medical College \& Reseach Institute, Mysore, E-mail: drskv2290@gmail.com
}

\begin{abstract}
Purpose: To evaluate the effects of tamsulosin, solifenacin, and combination therapy of two agents in improving the lower urinary tract symptoms of patients with indwelling Double-J (DJ) ureteral stents.

Materials and Methods: 274 patients underwent DJ Stenting anterogradely and retrogradely for post urinary stone disease treatment were randomly grouped into 4 groups and were removed in a mean of 14 days postoperatively. Group 1- no treatment (control Group), Group 2-received tamsulosin 0.4 mg once daily (Group 2), Group 3-recieved solifenacin $5 \mathrm{mg}$ once daily, and Group 4 combination. On preoperative day, postoperative day 1 and 14 all patients completed IPSS, QoL, VAPS questionnaire.
\end{abstract}

Results: The mean age was $39.22 \pm 11.92$ years. There was a significant difference in the IPSS total score between group 1 and groups 3 and 4. Group 4 also differed significantly from group 1 in the irritative subscore. The obstructive subscore differed between groups 2 and 4 and group 1. There was a statistically significant difference between group 1 and group 4 in the QoL score. There were no significant differences in the VAPS.

Conclusion: Combination therapy with tamsulosin and solifenacin improved both irritative and obstructive symptoms more than the other groups.

Keywords: DJ stents, tamsulosin, solifenacin, ureter, pain

\section{Abbreviations}

Double J stents - DJ stent; Visual Analogue Pain Scale-VAPS; QoL-Quality of Living; IPSS- International Prostate Symptom Score

\section{INTRODUCTION}

The use of ureteral stents in surgery was described as early as the 19th century [1]. Zimskind, however, in 1967 was the first to describe the cystoscopic placement of indwelling ureteral stents for obstructed ureters [2] (Zimskind et al, 1967). The first "double-J" (DJ) or double pigtail stent was developed almost simultaneously by Finney and Hepperlen [3] (Finney, 1978; Hepperlen et al, 1978). The use of DJ stents increased dramatically in urology departments worldwide, which had a tremendous positive impact on endourologic surgery and patient care. Today, ureteral stents are of fundamental importance to any urologic practice.
The double-J stent, which is the most common form of ureteral stent, is used in obstructive pyelonephritis, intolerable acute renal colic, ureteral edema, ureter perforation following endoscopic procedures, and diseases such as steinstrasse [4,5]. The patients experience various stent-related symptoms, such as pain, frequency, and urgency causing significant decrease in patient quality of life in both genders [6]. The etiology of these symptoms is unknown. Thomas in year 1993 reported that an important factor of stent-related symptoms is the reflux of urine due to pressure transmitted to the renal pelvis during urination, smooth muscle spasm and trigonal mucosal irritation by the intravesicular part of the stent [7]. 
To Evaluate the Effects of Tamsulosin, Solifenacin and Combination Therapy for the Treatment of Ureteral Stent Associated Symptoms

For this reason, several attempts to minimize stent-related symptoms have recently been reported.

Thus the pharmacologic management with selective alpha-1-blockers and antimuscarinic agents believed to be simpler and less invasive than other ways.

Tamsulosin $[8,9]$ acts as a selective inhibitor of $\alpha-1 \mathrm{a} / 1 \mathrm{~d}$-mediated contraction of the smooth muscles in distal ureter, bladder trigone, and bladder neck. It is thought that relaxing these smooth muscles decreases bladder outlet resistance and voiding pressure, with beneficial effect on stent related LUTS. Solifenacin [10, 11, 12] acts as a muscarinic receptor antagonist used for treatment of patients with overactive bladder $(\mathrm{OAB})$ and might be effective as well for stentrelated symptoms. The purpose of this article was therefore to analyze and assess the effectiveness of a selective alpha-1-blocker (tamsulosin) in combination with antimuscarinic (solifenacin) in improving the lower urinary tract symptoms of patients with indwelling double-J ureteral stents.

\section{MATERIALS AND MethodS}

\subsection{Materials}

During the period from January 2018 to December 2018, 295 patients were selected and 21 of them underwent bilateral DJ stenting who were excluded and 274 patients (195 men \&79 women) underwent DJ Stenting anterogradely and retrogradely by a single surgeon in the Department of Urology at K.R Hospital, MMC\&RI, Mysore and CSI HMH, Mysore with required eligibility criteria were considered in this study.

\subsection{Eligibility Criteria}

\subsubsection{Inclusion Criteria}

Patients aged more than 18 years undergoing Double-J stenting for urinary tract calculi were included in the study. These underwent thorough clinical, general, systemic examinations and the required investigational procedures to exclude any neurological, organic and systemic cause for their symptoms. Only those patients who had no obvious neurological, organic and systemic causes were included in the study.

\subsubsection{Exclusion Criteria}

Patients who met the following criteria were excluded from the study:
- Patient not willing for inclusion in the study.

- Age less than 18 years

- History of previous ureteral stenting

- Patient using analgesics before surgery.

- Patients who required bilateral DJ stenting.

- Pregnant woman.

- Previous urinary bladder pathology.

- Benign prostatic hyperplasia.

- Overactive bladder.

- Urinary tract infections.

- Previous use of selective alpha-1- blocker and/or antimuscarinic agent or hypersenisitivity to one or more alpha blockers.

\subsection{Methods}

On the screening visit detailed history, general examination and detailed urological examination was carried out and the enrolled patients were worked up as per protocol and data was recorded in data sheet. The surgery was performed under general/spinal anesthesia. A 5/5.5 $\mathrm{Fr}$ polyurethane ureteral stents were used in all patients. The position of the stent was confirmed by fluoroscopy. A total of 274 patients were chosen after assessing inclusion/exclusion criteria.

The patients were randomized into four groups:

- Group 1(n=69) was the control group and did not take any drugs.

- Group 2(n=66) received tamsulosin $0.4 \mathrm{mg}$ once a day every day.

- Group 3(n=67) received solifenacin $5 \mathrm{mg}$ once a day every day.

- Group4 $(n=72)$ received tamsulosin $0.4 \mathrm{mg}$ and solifenacin $5 \mathrm{mg}$ in combination daily.

\subsection{Patients Assessment and Outcome Measurements}

The day before surgery, on postoperative day 1 and on the on postoperative day 14, each patient completed written International Prostate Symptom Score/quality of life (IPSS/QoL) and visual analogue pain scale (VAPS) questionnaires.

The IPSS was divided into the total score, obstructive symptom score, and irritative 
To Evaluate the Effects of Tamsulosin, Solifenacin and Combination Therapy for the Treatment of Ureteral Stent Associated Symptoms

symptom score, and each was compared. Visual Analogue Pain Scale graded from 1(minimal or no symptoms) to 10 (symptoms of maximal severity). Each group's preoperative day, postoperative day 1 and post operative day 14 scores were compared.

Statistical analyses were performed with SPSS ver.18.0 (SPSS Inc., Chicago, IL, USA). Chisquare test, one way ANOVA, and one way repeated measure ANOVA were used for comparision between each of four groups. Values of $\mathrm{p}<0.05$ were considered statistically significant.

\section{RESULTS}

This study was a prospective, randomized and comparative study carried out between January 2018 and December 2018 to evaluate the effect of tamsulosin, solifenacin and combination therapy of the two agents in improving the lower urinary tract symptoms of patients with indwelling double-J ureteral stents.

A total of 295 patients were enrolled in the study and 21 patients who underwent bilateral stenting were excluded and 274 patients completed the study.

- Group 1(n=69) was the control group and did not take any drugs.

- Group 2(n=66) received tamsulosin $0.4 \mathrm{mg}$ once a day every day.

- Group 3(n=67) received solifenacin $5 \mathrm{mg}$ once a day every day.

- Group 4(n=72) received tamsulosin $0.4 \mathrm{mg}$ and solifenacin $5 \mathrm{mg}$ in combination daily.

The mean age of the patients was $39.22 \pm 11.92$ years, and there were no significant differences

Table1.

\begin{tabular}{|c|c|c|c|c|c|}
\hline & Group 1 & Group 2 & Group 3 & Group 4 & p-value ${ }^{a}$ \\
\hline Patient (n) & 69 & 66 & 67 & 72 & \multirow{4}{*}{$\begin{array}{l}0.957 \\
0.534\end{array}$} \\
\hline $\operatorname{Age}^{b}(y r)$ & $39.71 \pm 11.97$ & $39.31 \pm 11.22$ & $39.18 \pm 12.65$ & $38.67 \pm 11.85$ & \\
\hline \multicolumn{5}{|l|}{ Gender } & \\
\hline Male & 49 & 44 & 46 & 56 & \\
\hline Female & 20 & 22 & 21 & 16 & \\
\hline
\end{tabular}

$a$ : chi-square test, $b$ : Mean $\pm S D$

Table2.

\begin{tabular}{|l|l|l|l|l|l|c|}
\hline & $\begin{array}{l}\text { Group } \\
\mathbf{1}(\mathbf{n}=\mathbf{6 9})\end{array}$ & $\begin{array}{l}\text { Group } \\
\mathbf{2 ( n = 6 6 )}\end{array}$ & $\begin{array}{l}\text { Group } \\
\mathbf{3 ( n = 6 7 )}\end{array}$ & $\begin{array}{l}\text { Group } \\
\mathbf{4}(\mathbf{n}=\mathbf{7 2})\end{array}$ & Chi-Square test & p- value \\
\cline { 1 - 3 } URS & 43 & 40 & 47 & 52 & 0.90124 & \multirow{2}{*}{0.8351} \\
\cline { 1 - 2 } & 26 & 26 & 20 & 20 & & \\
\hline
\end{tabular}

between the groups. A total of 182 patients underwent URSL and 92 patients underwent PCNL.There were statistically significant differences in the IPSS total score and the obstructive sub score by one-way repeatedmeasures ANOVA ( $\mathrm{p}=0.013,0.006)$.

There were significant differences between group 1 and group $4(\mathrm{p}=0.015)$, and between group 2 and group $4(\mathrm{p}=0.031)$, in the IPSS total score. For the obstructive subscore, group 4 differed significantly from group $1(\mathrm{p}=0.003)$. There were no statistically significant differences in the irritative sub score, QoL, or VAPS ( $\mathrm{p}=0.075$, 0.068 , and 0.088 , respectively). However, the pvalue of interaction was statistically significant for the IPSS total score, irritative subscore, obstructive subscore, and QoL ( $\mathrm{p}<0.001,<0.001$, 0.015 , and 0.012 , respectively).

We therefore compared each group by one-way ANOVA at each time point. On the day of stent removal, all scores were significantly different in each group except the VAPS ( $<<0.001,<0.001$, $<0.001,<0.001$ ). In particular, all scores were significantly lower in group 4 except for VAPS. In group 2, only the obstructive score was significantly lower. The total and irritative sub score were significantly lower in group 3 . Preoperatively and 1 day postoperatively, there were no significant differences in any group. The VAPS did not appear to significantly change in any groups (Table 2). According to the multiple comparison test on the day of stent removal, there was a significant decrease only in group 4. This suggests that that stent-related symptoms improved more in group 4 than in group 1. Symptoms did not significantly improve in the other groups. The side effects of tamsulosin and solifenacin were minimal. No patients discontinued the medication because of side effects. 
To Evaluate the Effects of Tamsulosin, Solifenacin and Combination Therapy for the Treatment of Ureteral Stent Associated Symptoms

Table3. Comparisons of IPSS/QoL and VAPS in group 1, 2, 3 and 4

\begin{tabular}{|c|c|c|c|c|c|c|c|}
\hline & & Group 1 & Group 2 & Group 3 & Group 4 & pvalue $^{\text {a }}$ & pvalue $^{b}$ \\
\hline $\begin{array}{l}\text { IPSS total } \\
\text { score }\end{array}$ & $\begin{array}{l}\text { Preoperative } \\
\text { POD-1 } \\
\text { Day of stent } \\
\text { removal }\end{array}$ & $\begin{array}{l}8.54 \pm 3.96 \\
11.15 \pm 4.04 \\
13.45 \pm 3.50\end{array}$ & $\begin{array}{l}8.20 \pm 3.95 \\
12.03 \pm 4.45 \\
12.45 \pm 4.24\end{array}$ & $\begin{array}{l}8.64 \pm 3.77 \\
10.66 \pm 4.79 \\
10.72 \pm 4.29\end{array}$ & $\begin{array}{l}8.32 \pm 3.99 \\
10.97 \pm 3.64 \\
6.84 \pm 2.37\end{array}$ & 0.013 & $\begin{array}{l}0.958 \\
0.552 \\
<0.001\end{array}$ \\
\hline $\begin{array}{l}\text { IPSS } \\
\text { irritative } \\
\text { subscore }\end{array}$ & $\begin{array}{l}\text { Preoperative } \\
\text { POD-1 } \\
\begin{array}{l}\text { Day of stent } \\
\text { removal }\end{array}\end{array}$ & $\begin{array}{l}4.07 \pm 2.55 \\
6.40 \pm 3.42 \\
7.44 \pm 3.45\end{array}$ & $\begin{array}{l}4.22 \pm 2.80 \\
7.75 \pm 3.65 \\
8.01 \pm 3.83\end{array}$ & $\begin{array}{l}4.41 \pm 3.05 \\
6.23 \pm 3.96 \\
5.69 \pm 3.95\end{array}$ & $\begin{array}{l}4.76 \pm 2.67 \\
7.05 \pm 3.48 \\
4.18 \pm 2.65\end{array}$ & 0.075 & $\begin{array}{l}0.735 \\
0.201 \\
<0.001\end{array}$ \\
\hline $\begin{array}{l}\text { IPSS } \\
\text { obstructive } \\
\text { subscore }\end{array}$ & $\begin{array}{l}\text { Preoperative } \\
\text { POD-1 } \\
\text { Day of stent } \\
\text { removal }\end{array}$ & $\begin{array}{l}4.74 \pm 3.12 \\
5.18 \pm 2.54 \\
6.23 \pm 2.59\end{array}$ & $\begin{array}{l}4.25 \pm 2.91 \\
4.77 \pm 2.88 \\
4.66 \pm 3.20\end{array}$ & $\begin{array}{l}4.51 \pm 2.74 \\
4.86 \pm 2.70 \\
5.25 \pm 2.87\end{array}$ & $\begin{array}{l}3.83 \pm 2.51 \\
4.35 \pm 2.51 \\
2.88 \pm 2.02\end{array}$ & 0.006 & $\begin{array}{l}0.572 \\
0.592 \\
<0.001\end{array}$ \\
\hline QoL & $\begin{array}{l}\text { Preoperative } \\
\text { POD-1 } \\
\text { Day of stent } \\
\text { removal }\end{array}$ & $\begin{array}{l}2.47 \pm 1.76 \\
2.18 \pm 1.74 \\
2.77 \pm 1.70\end{array}$ & $\begin{array}{l}2.14 \pm 1.77 \\
2.41 \pm 1.69 \\
3.01 \pm 1.65\end{array}$ & $\begin{array}{l}2.37 \pm 1.59 \\
2.48 \pm 1.72 \\
2.81 \pm 1.75\end{array}$ & $\begin{array}{l}1.83 \pm 1.74 \\
2.31 \pm 1.54 \\
1.41 \pm 1.42\end{array}$ & 0.068 & $\begin{array}{l}0.385 \\
0.844 \\
<0.001\end{array}$ \\
\hline VAPS & $\begin{array}{l}\text { Preoperative } \\
\text { POD-1 } \\
\begin{array}{l}\text { Day of stent } \\
\text { removal }\end{array}\end{array}$ & $\begin{array}{l}6.35 \pm 1.67 \\
2.52 \pm 1.44 \\
2.80 \pm 1.60\end{array}$ & $\begin{array}{l}6.53 \pm 1.54 \\
2.84 \pm 1.47 \\
3.57 \pm 1.89\end{array}$ & $\begin{array}{l}6.11 \pm 1.64 \\
2.65 \pm 1.43 \\
2.77 \pm 1.82\end{array}$ & $\begin{array}{l}6.21 \pm 1.61 \\
2.40 \pm 1.34 \\
2.59 \pm 1.26\end{array}$ & 0.088 & \\
\hline
\end{tabular}

IPSS/QoL: International Prostate Symptom Score and Quality of Life, VAPS: Visual analogue pain scale, a: one-way repeated measures ANOVA, b: one-way ANOVA.

The mean age of the patients was $39.22 \pm 11.92$ years, and there were no significant differences between the groups (Table 1). As seen in Table 2 main indication of ureteral double $-\mathrm{J}$ stent placement was URS and PCNL, out of total 274 patients maximum no of patients $66.42 \%$ (182 out of 274) were URS cases and 33.58\% (92 out of 272) were PCNL cases. Between the two groups p-value was 0.8351 which was insignificant. There were statistically significant differences in the IPSS total score and the obstructive subscore by one-way repeatedmeasures ANOVA $(p=0.013,0.006)$. There were significant differences between group 1 and group $4(\mathrm{p}=0.015)$, and between group 2 and group $4(\mathrm{p}=0.031)$, in the IPSS total score. For the obstructive subscore, group 4 differed significantly from group $1 \quad(\mathrm{p}=0.003)$. There were no statistically significant differences in the irritative subscore, QoL, or VAPS ( $\mathrm{p}=0.075$, 0.068 , and 0.088 , respectively). However, the pvalue of interaction was statistically significant for the IPSS total score, irritative subscore, obstructive subscore, and QoL $(\mathrm{p}<0.001$, $<0.001,0.015$, and 0.012 , respectively).

We therefore compared each group by one-way ANOVA at each time point. On the day of stent removal, all scores were significantly different in each group except the VAPS $(\mathrm{p}<0.001$, $<0.001,<0.001,<0.001)$. In particular, all scores were significantly lower in group 4 except for VAPS.

In group 2, only the obstructive score was significantly lower. The total and irritative subscore were significantly lower in group 3 . Preoperatively and 1 day postoperatively, there were no significant differences in any group. The VAPS did not appear to significantly change in any groups (Table 3 ). According to the multiple comparison test on the day of stent removal, there was a significant decrease only in group 4. This suggests that those stent-related symptoms improved more in group 4 than in group 1. Symptoms did not significantly improve in the other groups. The side effects of tamsulosin and solifenacin were minimal. No patients discontinued the medication because of side effects.

\section{DISCUSSION}

The present study was a prospective, randomized and comparative study carried out between January 2018 and December 2018 in the Department of Urology, at K.R Hospital MMC\&RI, Mysore and CSI HMH, Mysore to evaluate the effect of tamsulosin, solifenacin and combination therapy of the two agents in improving the lower urinary tract symptoms of patients with indwelling double-J ureteral stents.

A total of 295 patients were enrolled in the study and 21 patients who underwent bilateral 
To Evaluate the Effects of Tamsulosin, Solifenacin and Combination Therapy for the Treatment of Ureteral Stent Associated Symptoms

stenting were excluded and 274 patients completed the study.

- Group 1(n=69) was the control group and did not take any drugs.

- Group 2(n=66) received tamsulosin $0.4 \mathrm{mg}$ once a day every day.

- Group 3(n=67) received solifenacin $5 \mathrm{mg}$ once a day every day.

- Group 4(n=72) received tamsulosin $0.4 \mathrm{mg}$ and solifenacin $5 \mathrm{mg}$ in combination daily.

The results of this prospective, randomized, controlled trial showed that, the combined use of tamsulosin and solifenacin improved the QoL and alleviated LUTS associated with double-J ureteral stents, better than either drug alone and well tolerated.

Stent discomfort is believed to affect over $80 \%$ of patients [13, 14, 15, 16]. Patients with indwelling stents have been known to complain of a variety of stent-related symptoms, typically: storage, voiding, OAB symptoms, haematuria, and pain. These symptoms are believed to be unavoidable and associated with reduced healthrelated quality of life.

Damiano et al [8] reported that there was no symptoms difference between stent with different size, whereas there was a tendency of small diameter stents to dislodge more often.

Chew et al [17] reported that changing in body position led to movement of distal end within the bladder and induced more trigonal irritation and stent related symptoms.

Lang and associates [18] stated that a possible mechanism of relief of stent-related symptoms could be smooth muscle relaxation of lower ureter and trigone as well as reducing ureteric motility.

Wang and his colleagues [19] suggested that relaxation of bladder neck/prostatic smooth muscle, with consequent reduction in voiding pressure and urinary reflux, is other possible mechanisms for control of stent related symptoms, setting a rationale behind using alpha blockers in overcoming ureteral stent symptoms.

The Quality Of Life scores at pre-insertion and POD-1 in groups I to IV were nonsignificant i.e $\mathrm{p}$ value was 0.385 and 0.844 at pre-insertion and POD-1 respectively. At 2 weeks after insertion there was significant difference in scores $(p$ value was 0.001) with minimum score in combination therapy and maximum score in control group.

The effectiveness of alpha blockers in controlling double-J stent-related symptoms was reported previously by Wang et al [19] in a prospective randomized study comparing tamsulosin to placebo in 79 patients using (USSQ) reported that tamsulosin improved stent related urinary symptoms, QoL, and they recommended its routine use.

Also Damiano et al [8] reported that administration of tamsulosin has a positive effect on stent-related urinary symptoms, QoL, and VAPS, although this study was not doubleblinded or placebo-controlled.

Also, several studies reported that other alphablocker alfuzosin improved stent-related symptoms and quality of life and reduced analgesic demand compared to the placebo group. [20,21]

Kuyumcuoglu et al [22] reported in a prospective randomized study that tamsulosin was not different than placebo in controlling stent-related symptoms. Similarly, Lee et al.[23] reported in a prospective, randomized, and placebo-controlled study that postoperative solifenacin use was effective and well tolerated for the treatment of LUTS, stent-related body pain, and hematuria irrespective of gender in patients undergoing ureteroscopic lithotripsy (URSL) and double-J stent indwelling.

\section{CONCLUSION}

Combination therapy with tamsulosin and solifenacin improved obstructive and irritative symptoms and QoL more than in the control group. Therefore, combination therapy with tamsulosin and solifenacin should be strongly considered for patients who complain of stentrelated symptoms. In the future, large-scale, prospective, and randomized study will be needed.

\section{REFERENCES}

[1] Shoemaker GE. IV. An improvement in the technique of catheterization of the ureter in the female. Ann Surg 1895; 22:650-4.

[2] Zimskind PD, Fetter TR, Wilkerson JL. Clinical use of long-term indwelling silicone rubber ureteral splints inserted cystoscopically. J Urol 1967; 97:840-4.

[3] Hepperlen TW, Mardis HK, Kammandel H. Self-retained internal ureteral stents: a new approach. J Urol 1978; 119:731-4. 
To Evaluate the Effects of Tamsulosin, Solifenacin and Combination Therapy for the Treatment of Ureteral Stent Associated Symptoms

[4] Chew BH, Knudsen BE, Denstedt JD. The use of stents in contemporary urology. Curr Opin Urol 2004; 14:111-5.

[5] Jeong H, Kwak C, Lee SE. Ureteric stenting after ureteroscopy for ureteric stones: a prospective randomized study assessing symptoms and complications. BJU Int 2004; 93:1032-4.

[6] Joshi HB, Stainthorpe A, Keeley FX Jr, MacDonagh R, Timoney AG. Indwelling ureteral stents: Evaluation of quality of life to aid outcome analysis. J Endourol 2001; 15:151-4.

[7] Thomas R. Indwelling ureteral stents: impact of material and shape on patient comfort. J Endourol 1993; 7:137-40.

[8] Damiano R, Autorino R, De Sio M, Giacobbe A, Palumbo IM, D Armiento M. Effect of tamsulosin in preventing ureteral stentrelated morbidity: a prospective study. J Endourol 2008; 22:651-6.

[9] Beiko DT, Knudsen BE, Denstedt JD. Advances in ureteral stent design. J Endourol 2003; 17:195-9.

[10] M.-S.Choo,J.Z.Lee,J.B.Lee et al.,"Efficacy and safety of solifenacin succinate in Korean patients with overactive bladder: a randomised, prospective, double-blind, multicentre study," InternationalJournalofClinicalPractice,vol.62,n o.11, pp.1675-1683,2008.

[11] Y. J. Lee, K. H. Huang, H. J. Yang, H. C. Chang, J. Chen, and T.K.Yang, "Solifenacin improves double-J stent-related symptoms in both genders following uncomplicated uretero scopic lithotripsy, "Urolithiasis, vol.41, pp.247252,2013.

[12] K. Ugur, E. Bilal, T. Murat, F. Gokhan, T. Fatih, and O. Aydin, "Effectiveness of medical treatment in overcoming the ureter all double $\mathrm{J}$ stent related symptoms ,"Canadian Urological Association Journal,vol.6,no.6,pp.234-237,20 12.

[13] Chew BH, Knudsen BE, Denstedt JD. The use of stents in contemporary urology. CurrOpin Urol 2004; 14:111-5.

[14] Jeong H, Kwak C, Lee SE. Ureteric stenting after ureteroscopy for ureteric stones: a prospective randomized study assessing symptoms and complications. BJU Int 2004; 93:1032-4.

[15] Leventhal EK1, Rozanski TA, Crain TW, Deshon GE Jr. Indwelling ureteral stents as definitive therapy for distal ureteral calculi. J Urol. 1995 Jan; 153(1):34-6.

[16] Saltzman B.Ureteral stents. Indications, variations, and complications. Urol Clin North Am. 1988 Aug;15(3):481-91

[17] B.H.Chew, B.E. Knudsen, L. Nottetal., "Pilot study of ureteral movement in stented patients: first step in understanding dynamic ureteral anatomy to improve stent comfort," Journal of Endourology, vol.21,no.9,pp.1069-1075, 2007.

[18] R. J. Lang, M. E. Davidson, and B. Exintaris, "Pyeloureteral motility and ureteral peristalsis: essential role of sensory nerves and endogenous prostaglandins," Experimental Physiology,vol. 87,no.2,pp.129-146,2002.

[19] C.J.Wang,S.W.HuangandC.-H.Chang,"Effects of tamsulosin on lower urinary tract symptoms due to double-j stent: a prospective study," UrologiaInternationalis, vol.83,no.1,pp.66-69, 2009

[20] El-Nahas AR1, El-Assmy AM, Shoma AM, Eraky I, El-Kenawy MR, El-Kappany HA. Self-retaining ureteral stents: analysis of factors responsible for patients' discomfort J Endourol. 2006 Jan; 20(1):33-7.

[21] Itoh Y, Kojima Y, Yasui T, Tozawa K, Sasaki S, Kohri K. Examination of alpha 1 adrenoceptor subtypes in the human ureter.Int $\mathbf{J}$ Urol. 2007 Aug;14(8):749-53

[22] U. Kuyumcuoglu, B. Eryildirim, M. Tuncer, G. Faydaci, F. Tarhan, and A. Ozg"ul, "Effecti veness of medical treatment in overcoming the ureteral double-J stent related symptoms," Canadian Urological Association Journal,vol.6, no.6,pp.E234-E237,2012

[23] Lee SJ, Yoo C, Oh CY, Lee YS, Cho ST, Lee $\mathrm{SH}$, et al. Stent position is more important than alpha-blockers or anticholinergics for stentrelated lower urinary tract symptoms after ureteroscopic ureterolithotomy: a prospective randomized study. Korean J Urol 2010; 51:63641.

Citation: Dr Prakash H S, Dr Sunil Kumar V. To Evaluate the Effects of Tamsulosin, Solifenacin and Combination Therapy for the Treatment of Ureteral Stent Associated Symptoms. ARC Journal of Urology.2019; 4(3): 12-17.doi:dx.doi.org/10.20431/2456-060X.0403003.

Copyright: () 2019 Authors. This is an open-access article distributed under the terms of the Creative Commons Attribution License, which permits unrestricted use, distribution, and reproduction in any medium, provided the original author and source are credited. 